\title{
Plasticity during Motherhood: Changes in Excitatory and Inhibitory Layer 2/3 Neurons in Auditory Cortex
}

\author{
Lior Cohen and Adi Mizrahi \\ Department of Neurobiology, Institute of Life Sciences, Edmond and Lily Safra Center for Brain Sciences, Hebrew University of Jerusalem, Edmond J. Safra \\ Campus, Givat Ram Jerusalem, 91904, Israel
}

\begin{abstract}
Maternal behavior can be triggered by auditory and olfactory cues originating from the newborn. Here we report how the transition to motherhood affects excitatory and inhibitory neurons in layer $2 / 3$ (L2/3) of the mouse primary auditory cortex. We used in vivo twophoton targeted cell-attached recording to compare the response properties of parvalbumin-expressing neurons (PVNs) and pyramidal glutamatergic neurons (PyrNs). The transition to motherhood shifts the average best frequency of PVNs to higher frequency by a full octave, with no significant effect on average best frequency of PyrNs. The presence of pup odors significantly reduced the spontaneous and evoked activity of PVN. This reduction of feedforward inhibition coincides with a complimentary increase in spontaneous and evoked activity of PyrNs. The selective shift of PVN frequency tuning should render pup odor-induced disinhibition more effective for high-frequency stimuli, such as ultrasonic vocalizations. Indeed, pup odors increased neuronal responses of PyrNs to pup ultrasonic vocalizations. We conclude that plasticity in the mothers is mediated, at least in part, via modulation of the feedforward inhibition circuitry in the auditory cortex.
\end{abstract}

Key words: feed-forward inhibition; motherhood; pup odors; ultrasonic vocalizations

\section{Introduction}

Becoming a mother is a major natural experience associated with different forms of physiological and neuronal changes (Brunton and Russell, 2008; Leuner et al., 2010). The underlying effect of these changes on emerging maternal behaviors and sensory processing within the mother's brain are essentially unknown. In mammals, a set of maternal behaviors is regulated by auditory and olfactory cues originating from the newborn (Lévy et al., 2004; Ehret, 2005; Brunton and Russell, 2008; Brudzynski, 2009; Lévy and Keller, 2009; Scattoni et al., 2009; Swain et al., 2011; Lundström et al., 2013). Prompt and adequate maternal response to these cues is crucial for the newborn's survival. Mice are becoming a strong model to study the underlying mechanisms of brain plasticity in the context of motherhood (Dulac et al., 2014).

Behaviorally, mouse ultrasonic vocalizations (USVs) are produced by young pups that are unable to maintain their body temperature (Sewell, 1970; Noirot, 1972; Smotherman et al., 1974; Hahn and Lavooy, 2005; Scattoni et al., 2009). USVs prompt the mother to search and retrieve the isolated pup to the

\footnotetext{
Received May 2, 2014; revised Dec. 3, 2014; accepted Dec. 4, 2014.

Author contributions: L.C. and A.M. designed research; L.C. performed research; L.C. analyzed data; L.C. and A.M. wrote the paper.

This work was supported by European Research Council Grant 203994 (A.M.), the Gatsby Charitable Foundation, and the Max Planck Hebrew University Center for Sensory Processing of the Brain in Action. L.C. was supported by a fellowship from the Edmond and Lily Safra Center for Brain Sciences. We thank members of the Mizrahi laboratory for comments and discussions. We thank Eli Nelken on advice on statistics.

The authors declare no competing financial interests.

Correspondence should be addressed to Prof. Adi Mizrahi at the above address. E-mail: mizrahi.adi@mail.huji.ac.il.

DOI:10.1523/JNEUROSCI.1786-14.2015

Copyright $\odot 2015$ the authors $\quad 0270-6474 / 15 / 351806-10 \$ 15.00 / 0$
}

nest. In mice, cortical neurons of females after their first reproductive cycle detect and discriminate USVs better than in naive virgins (Liu et al., 2006; Liu and Schreiner, 2007). In addition to pup vocalization, other non-auditory cues become behaviorally significant for mothers. Notably, pup body odors have been shown to inform the mother of the presence of her pups (Smotherman et al., 1974; Lévy et al., 2004; Lévy and Keller, 2009; Lundström et al., 2013; Okabe et al., 2013). USVs and pup odors often come together when perceived by the mother. Therefore, the mother may learn the contingency between these stimuli to identify and locate distressed pups (Smotherman et al., 1974; Cohen et al., 2011; Okabe et al., 2013). We showed recently that pup odors reshape neuronal responses to sounds in the primary auditory cortex (A1) of lactating mothers (Cohen et al., 2011). This interaction between smells and sounds had heterogeneous effects on pure tone responses in A1. The observed heterogeneity in the study by Cohen et al. (2011) could have been a direct result of cell type and layer heterogeneity. Interestingly, pup odors had a more homogeneous effect on responsiveness to USVs: almost exclusively increased responsiveness. However, the cortical mechanism facilitating this increased responsiveness to USVs remains unclear.

The neocortex is a layered structure composed of various types of cells. Eighty percent of cortical neurons are pyramidal glutamatergic principal neurons (PyrNs), whereas 20\% are interneurons (INs). Different types of INs with different forms of connectivity have been described recently (Xu et al., 2010; Fino et al., 2013; Pfeffer et al., 2013). One major group is the parvalbumin-expressing neurons (PVNs) that provide feedforward inhibition onto PyrNs (Freund and Katona, 2007; Fino et al., 2013). Feedforward inhibition controls selectivity, gain, and 
integration time of PyrNs, therefore generating contrast and precision of responses. In the auditory cortex, sounds that acquire behavioral meaning (including USVs) show increased evoked responses, and these changes were suggested to be mediated via feedforward inhibition (Galindo-Leon et al., 2009; O'Connell et al., 2011). Here, we asked whether the transition to motherhood affects the response properties of layer 2/3 (L2/3) PVNs and PyrNs in a more homogeneous manner and, if so, how?

\section{Materials and Methods}

Animals and surgical procedure. All experimental procedures used in this study were approved by the Hebrew University Animal Care and Use Committee. PV-Cre (Hippenmeyer et al., 2005) and a Cre-dependent tdTomato reporter strain Ai9 (Madisen et al., 2010) were obtained from The Jackson Laboratory (background strain C57BL/6). A total of 39 10to 12-week-old, PV-Cre;Ai9 double-heterozygous female mice $(\mathrm{PV} \times$ Ai9) were used. Thirty-seven mice were used for in vivo electrophysiology experiments and two for histology. Naive virgins $(n=16)$ are female mice that were never housed with males or pups after they had been weaned at postnatal day $21(\mathrm{P} 21)$. Lactating mothers $(n=21)$ are females $4 \mathrm{~d}$ after parturition ( $\mathrm{P} 4 \pm 12 \mathrm{~h}$ ), nursing a litter of at least five pups and displaying normal maternal behavior (i.e., pup retrieval and nesting).

Animals were anesthetized with an intraperitoneal injection of ketamine and medetomidine ( 0.80 and $0.65 \mathrm{mg} / \mathrm{kg}$, respectively) and a subcutaneous injection of Carprofen $(0.004 \mathrm{mg} / \mathrm{g})$. Additionally, dextrose-saline was injected to prevent dehydration. Experiments lasted up to $8 \mathrm{~h}$. The depth of anesthesia was assessed by monitoring the pinch withdrawal reflex, and ketamine/medetomidine was added to maintain it. The animal's rectal temperature was monitored continuously and maintained at $36 \pm 11^{\circ} \mathrm{C}$. For imaging and recording, a custom-made metal pin was glued to the skull using dental cement and connected to a custom stage to allow precise positioning of the head relative to the speaker (facing the right ear). The muscle overlying the left auditory cortex was removed, and a craniotomy $(\sim 2 \times 2 \mathrm{~mm})$ was performed over A1 (coordinates, $2.3 \mathrm{~mm}$ posterior and $4.2 \mathrm{~mm}$ lateral to bregma) as described previously (Stiebler et al., 1997; Rothschild et al., 2010; Cohen et al., 2011).

Immunohistochemistry and microscopy. For Figure $1 a$, coronal sections $(40 \mu \mathrm{m})$ of A1 were treated with anti-PV antibodies (rabbit anti-PV, 1:1000 in blocking solution; Swant) overnight, washed with PBS, and then incubated for another $2 \mathrm{~h}$ with a secondary antibody (goat antirabbit Cy5, 1:250; Millipore Bioscience Research Reagents). Slices were imaged by a Leica SP50 confocal microscope equipped with a $40 \times(1.25$ numerical aperture) Leica oil-immersion objective. Counting of neuronal somata was performed manually from the confocal images of three A1 slices. Each somata was scored as labeled with tdTomato, Cy5, or both.

Imaging and electrophysiology. Cell-attached recordings were obtained using blind/targeted patch-clamp recording by a previously described procedure (Margrie et al., 2003; Kitamura et al., 2008; Judkewitz et al., 2009; Cohen et al., 2011, 2013). Imaging of Al was performed using an Ultima two-photon microscope from Prairie Technologies equipped with a $16 \times$ water-immersion objective lens $(0.8$ numerical aperture; CF175; Nikon). Two-photon excitation of the electrode and somata was used at $930 \mathrm{~nm}$ (DeepSee femtosec laser; Spectraphysics). At the end of the electrical recording, fluorescent dye in the electrode (Alexa Flour$488 ; 50 \mu \mathrm{M}$ ) was injected into the cell using negative current pulses. The recording depths of cell somata were restricted to subpial depths of $180-$ $420 \mu \mathrm{m}$, documented by the micropipette manipulator and multiphoton imaging (Table 1). Per animal, all recordings were made within $<200 \mu \mathrm{m}$ between them (in the $x$-, $y$-, and $z$-axes).

Auditory and olfactory stimuli. USVs were recorded with a one-quarter inch microphone (Brüel \& Kjær) from P4-P5 PV $\times$ Ai9 pups $(n=3)$. Vocalizations were sampled at $500 \mathrm{kHz}$ and identified offline (Digidata 1322A; Molecular Devices). The auditory protocol comprised two played-back USVs and 18 pure tones ( $100 \mathrm{~ms}$ duration, $3 \mathrm{~ms}$ on and off linear ramp) logarithmically spaced and presented at four sound pressure levels (SPLs; 72-24 dB). Each stimulus/SPL combination was presented
20 times at a rate of $1.25 \mathrm{~Hz}$ (total of 1600 stimuli presented in random order).

The olfactory-auditory experimental procedure. Pup body odors were delivered as described previously (Cohen et al., 2011). The olfactoryauditory protocol consisted of playing the auditory protocol while streaming clear air to the nose of the animal, followed by 1 min of pupodor delivery before playing the set of auditory stimuli again while continuously streaming the pup odors ( $\sim 50$ min recording time). An interval of 30 min clear-air "wash" separated consecutive cell recordings within animals.

Data analysis. Data analysis and statistics were performed using custom-written code in MATLAB (MathWorks). Spikes were extracted from raw voltage traces by thresholding. Spike times were then assigned to the local peaks of suprathreshold segments and rounded to the nearest millisecond. For each cell, we extracted six parameters, as follows. (1) For spontaneous firing rate, all trials were assigned to a raster plot according to their chronological order. The spontaneous firing rate of the cell was calculated based on the $100 \mathrm{~ms}$ preceding each stimulus presentation. (2) For response latency and response window, the response latency of each cell was scored by two approaches. First, the onset of evoked response was determined as the timing of the first action potential peak (positive peak in loose-patch recording) occurring within a 10-60 ms time window after stimulus onset (pure tones at $72 \mathrm{~dB} \mathrm{SPL}$ ). The cell response latency was considered as the first time point at which average spike count exceeded 2 SDs of the baseline spike rate (in $1 \mathrm{~ms}$ bins). The second approach for calculating response latency is to distinguish spontaneous from stimulus-driven spikes. This approach was adopted from an algorithm developed by others and described in detail previously (Chase and Young, 2007). Both approaches produced indistinguishable results and did not affect any of the conclusions presented here. For simplification, we present our result using the first approach. (3) The evoked response is the relative increase in spike rates (evoked-spontaneous) in a $60 \mathrm{~ms}$ response window starting from the calculated cells response latency (see above). The rate of evoked spikes was averaged across all SPLs to represent the evoked response of the cell. (4) The maximum evoked response is the maximum rate of spikes (over 20 repetitions) evoked by a stimulus/ SPL combination. (5) The evoked response width is the half-maximum half-width of the peristimulus time histogram (PSTH) of the cells. (6) Best frequency (BF) is the tone frequency that elicited the strongest response across all SPLs. 7) For the modulation index, the modulation of pup odor on different cell properties was normalized to each cell and the specific parameter tested. For example, for spontaneous spike rate (SSR), the modulation index was calculated as follows: modulation index $\mathrm{SSR}_{\mathrm{SR}}=$ $\left[\left(\mathrm{SSR}_{\text {pup odor }}-\mathrm{SSR}_{\text {air }}\right) /\left(\mathrm{SSR}_{\text {pup odor }}+\mathrm{SSR}_{\mathrm{air}}\right)\right]$.

\section{Results}

\section{Identification of PVNs and PyrNs}

To visually identify PVNs in vivo, we used a PV-Cre mouse crossed to a cre-dependent tdTomato reporter $(\mathrm{PV} \times \mathrm{Ai}$ ) $)$. In A1 of these mice, tdTomato is expressed mostly in PVNs as confirmed by immunohistochemistry (Fig. 1a). We used in vivo twophoton microscopy to visually target electrical recordings from tdTomato-expressing $\left(\right.$ tdTomato $\left.^{+}\right)$cells $(n=95)$ and nonlabeled cells $(n=97)$ and restricted the recordings to L2/3 (Table 1 , Depth). To avoid sampling bias, our recordings were acquired strictly within local circuits (within $<200 \mu \mathrm{m}$ between cells). In addition, in several mice from each experimental group, we were able to sample neighboring neurons of both cell types ( $~ 50 \%$ of cells; Fig. 1b). All neurons were collected from mice under ketamine anesthesia. At the end of each recording, we injected dye into the somata of recorded cells, thus unambiguously indentifying cell identity (Fig. 1b). We analyzed the spike waveform of all neurons, verifying that tdTomato ${ }^{+}$cells in L2/3 had faster/narrower spikes relative to tdTomato-negative (tdTomato ${ }^{-}$) cells (Fig. 1b,c; Wu et al., 2008; Yazaki-Sugiyama et al., 2009; Oswald and Reyes, 2011). Therefore, tdTomato ${ }^{+}$cells are regarded as fast-spiking PVNs. Given that the neocortex comprises mostly 
b

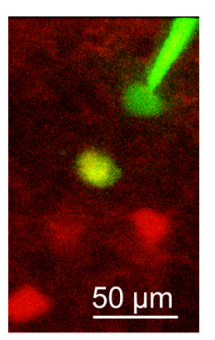

Anti PV tdTomato a

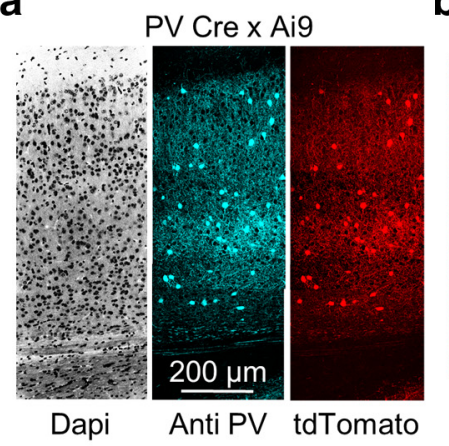

d

d

PV Cre x Aig
72

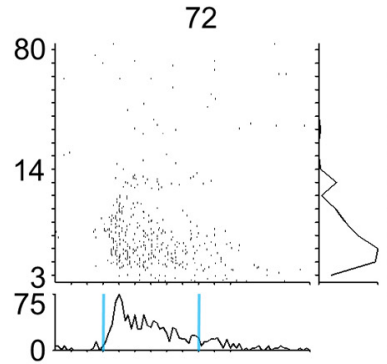

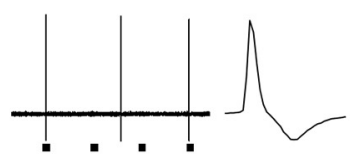

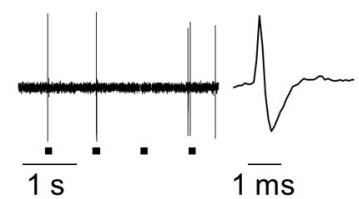

C

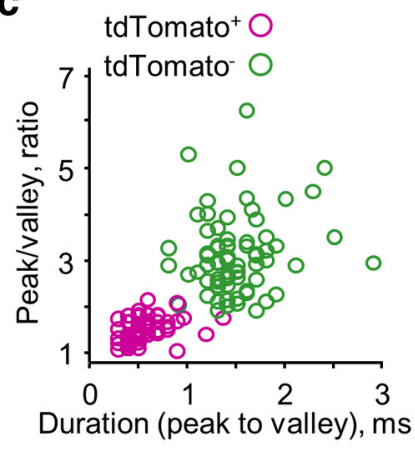

Naïve virgin
56

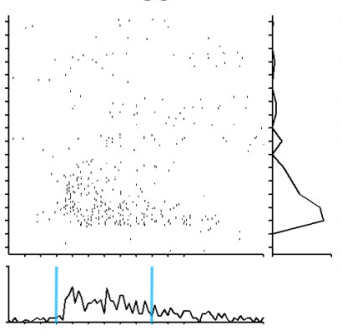

40

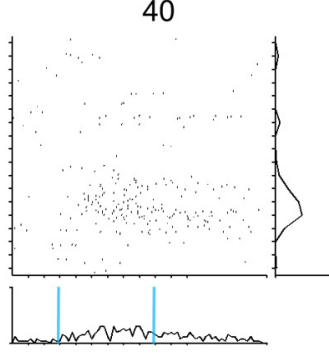

24

$\mathrm{dB}, \mathrm{SPL}$
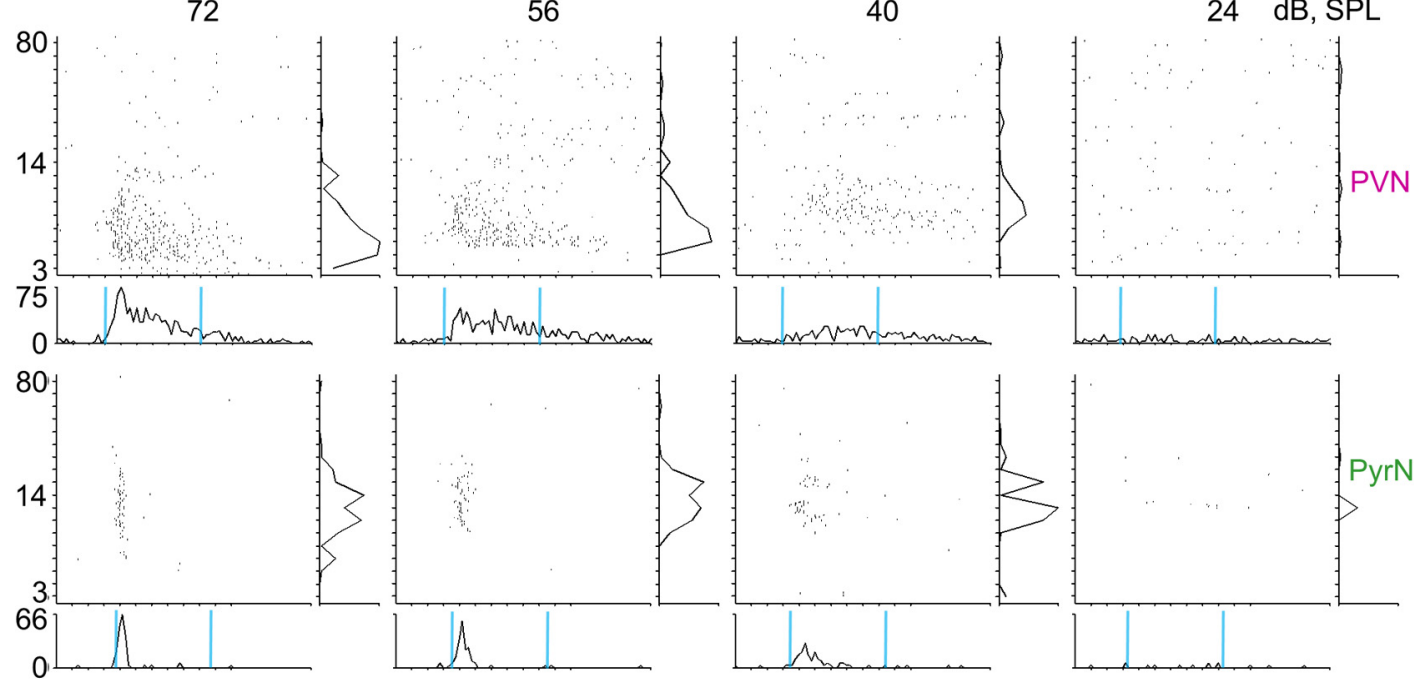

Lactating mother
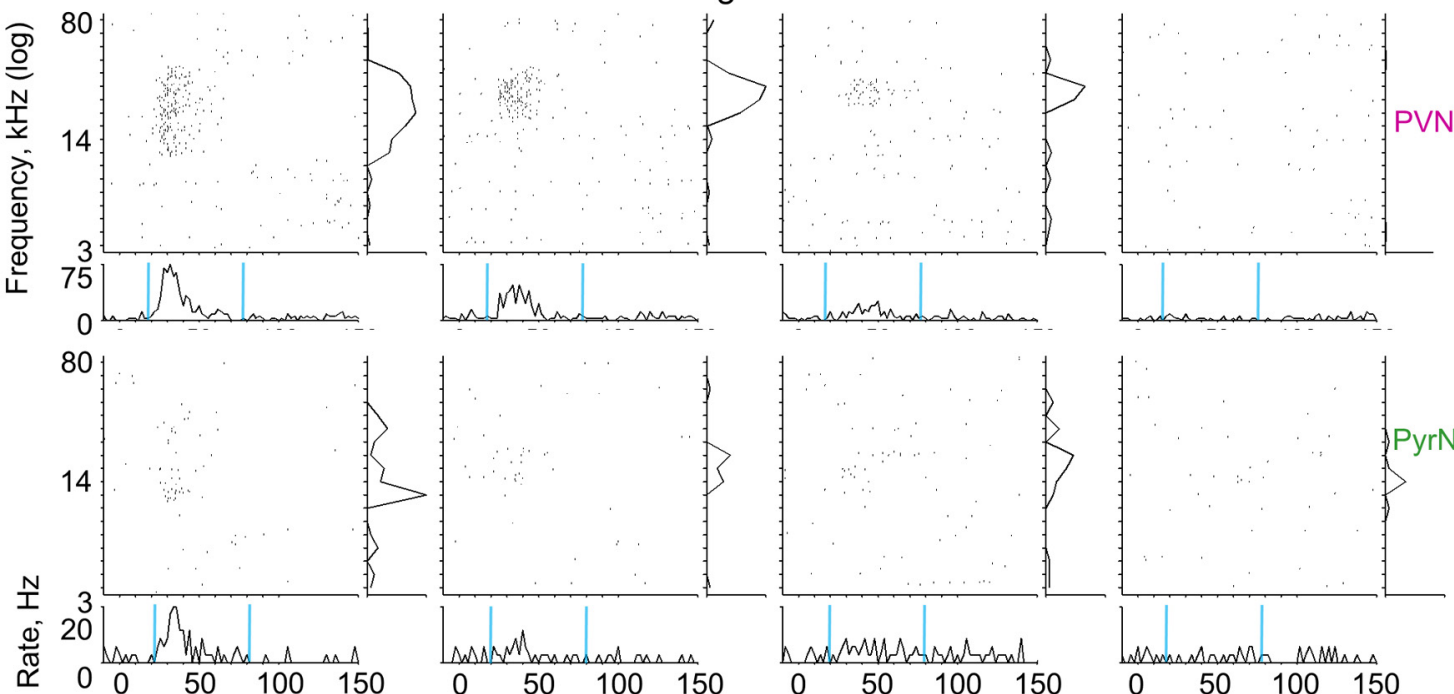

Time from stimuli onset, $\mathrm{ms}$

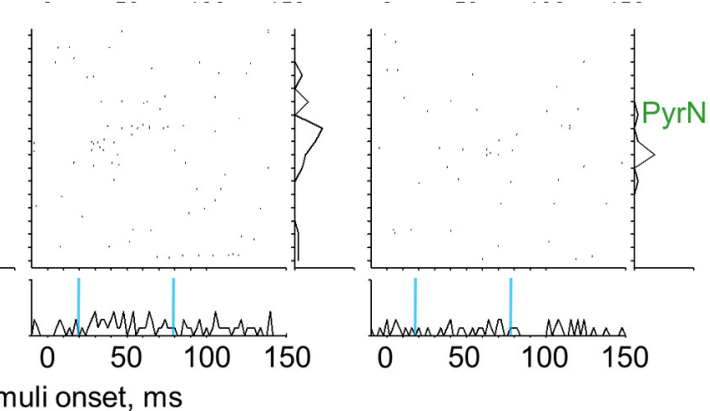

Figure 1. Single-cell recordings of PVNs and PyrNs. $\boldsymbol{a}$, Immunohistochemical confirmation of parvalbumin-expressing IN labeling in PV-Cre;Ai9 double-heterozygous mice (A1 coronal sections of $40 \mu \mathrm{m}$ ). The vast majority (144 of 145) of tdTomato ${ }^{+}$cells were labeled by the anti-PV antibodies. $\boldsymbol{b}$, Representative examples of targeted recordings (top, tdTomato ${ }^{-}$cell; bottom, tdTomato ${ }^{+}$ cell). Left, Confirmation of electrode targeting. Two-photon micrograph of tdTomato ${ }^{+}$cells (red) and the recording electrode (Alexa Fluor-488, green). The yellow cell is a tdTomato ${ }^{+}$cell after targeted recording and injection of green dye from the electrode. Middle, Electrical recording of spike output of tdTomato ${ }^{-}$(top) and tdTomato ${ }^{+}$(bottom) cells that are shown at the two-photon micrograph on the left (gray rectangles indicate tone stimuli). Right, Individual spike waveforms. c, Spike waveform analysis. Cells expressing tdTomato had characteristic low peak/valley ratio $<2$ (71 of 73 cells) and fast peak to valley duration $<1 \mathrm{~ms}$ ( 71 of 73 cells). tdTomato ${ }^{-}$cells had a higher peak/valley ratio $>2$ ( 68 of 74 cells) and slower peak to valley duration $>1 \mathrm{~ms}$ ( 70 of 74 cells). $\boldsymbol{d}$, Four examples of single-cell responses. The two cell types are each from a single mouse (1 pair per experimental group). For each plot, the top are raster plots in response to pure tones shown separately for all SPLs, and the bottom shows PSTHs by SPL (spikes/2 ms bins, relative to response at $72 \mathrm{dBSPL}$ ). The cyan vertical lines indicate a $60 \mathrm{~ms}$ response window starting from the calculated time of response latency. Right, Frequency tuning curve (evoked spikes/stimulus, normalized to response at $72 \mathrm{~dB} S \mathrm{SL}$ ). 
Table 1. Physiological properties of PVNs and PyrNs across the dataset

\begin{tabular}{|c|c|c|c|c|c|c|c|c|c|}
\hline Group & Animals $(n)$ & Cells $(n)$ & $\begin{array}{l}\text { Depth } \\
(\mu \mathrm{m})\end{array}$ & $\begin{array}{l}\text { Spontaneous } \\
\text { spike rate } \\
(\mathrm{Hz})\end{array}$ & $\begin{array}{l}\text { Maximum } \\
\text { evoked } \\
\text { response }(\mathrm{Hz})\end{array}$ & $\begin{array}{l}\text { Evoked } \\
\text { response } \\
(\mathrm{Hz})\end{array}$ & $\begin{array}{l}\text { Response } \\
\text { latency (ms) }\end{array}$ & $\mathrm{BF}(\mathrm{kHz})$ & $\begin{array}{l}\text { Response } \\
\text { width } \\
(50 \%) \text { (ms) }\end{array}$ \\
\hline NV, PyrN & 11 & 39 & $307 \pm 51$ & $0.18 \pm 0.21$ & $14.1 \pm 7.3$ & $1.23 \pm 1.02$ & $30.2 \pm 8.0$ & $10.1 \pm 5.5$ & $10.9 \pm 5.5$ \\
\hline LM, PyrN (A) & \multirow[t]{3}{*}{18} & 35 & $331 \pm 67$ & $0.70 \pm 1.19$ & $12.3 \pm 13.1$ & $0.84 \pm 1.17$ & $29.2 \pm 10.7$ & $12.6 \pm 7.5$ & $14.6 \pm 7.4$ \\
\hline LM, PyrN (0) & & - & - & $1.11 \pm 1.57$ & $16.1 \pm 12.8$ & $1.08 \pm 1.33$ & $27.0 \pm 11.0$ & $17.1 \pm 14.5$ & $19.3 \pm 9.2$ \\
\hline LM, PVN (A) & & 35 & $302 \pm 53$ & $2.45 \pm 3.11$ & $27.7 \pm 9.5$ & $2.37 \pm 2.17$ & $21.3 \pm 4.6$ & $18.8 \pm 10.8$ & $19.1 \pm 15.8$ \\
\hline NV, PyrN (A) & 5 & 23 & $328 \pm 53$ & $0.32 \pm 0.31$ & $13.8 \pm 10.4$ & $1.05 \pm 0.88$ & $30.2 \pm 7.4$ & $10.1 \pm 5.9$ & $10.0 \pm 4.2$ \\
\hline NV, PyrN (0) & & - & - & $0.33 \pm 0.30$ & $13.4 \pm 10.9$ & $0.98 \pm 0.85$ & $30.5 \pm 6.9$ & $10.5 \pm 5.9$ & $9.2 \pm 2.8$ \\
\hline NV, PVN (A) & & 7 & $344 \pm 61$ & $3.10 \pm 1.98$ & $31.7 \pm 15.4$ & $3.44 \pm 2.26$ & $23.0 \pm 2.5$ & $9.8 \pm 4.7$ & $17.9 \pm 5.7$ \\
\hline NV, PVN (0) & & - & - & $3.46 \pm 2.42$ & $32.0 \pm 16.1$ & $3.51 \pm 1.72$ & $23.1 \pm 2.5$ & $9.4 \pm 4.0$ & $17.3 \pm 4.4$ \\
\hline $\mathrm{LM}, \operatorname{PVN}(0)^{a}$ & 3 & 15 & $312 \pm 79$ & $1.71 \pm 2.84$ & $25.4 \pm 14.9$ & $1.63 \pm 1.45$ & $21.5 \pm 5.9$ & $17.8 \pm 10.1$ & $17.6 \pm 12.6$ \\
\hline
\end{tabular}

All values are mean \pm SD. A, Clear air; 0 , pup body odor; NV, naive virgins; LM, lactating mothers.

${ }^{a}$ Cells recorded in lactating mothers in which pup odor was constant throughout the experiment.

( $\sim 80 \%$ ) PyrNs whereas PVNs account for $\sim 40 \%$ of cortical INs (Markram et al., 2004; Xu et al., 2010; Pfeffer et al., 2013), we consider tdTomato ${ }^{-}$cells as good proxy for PyrNs.

\section{Basic response properties of L2/3 PVNs and PyrNs}

To evaluate response properties of PVNs and PyrNs, we recorded the spiking responses of single neurons to pure tones $(3-80 \mathrm{kHz})$ at four SPLs (72-24 dB SPL). Four representative examples of the type of responses we recorded are shown in Figure 1d (one PVN and one PyrN recorded within the same animal from each experimental group). We extracted the following parameters for each cell: (1) BF; (2) spontaneous spike rate; (3) evoked response latency; (4) evoked response spike rate; (5) maximal evoked spike rate per trial; and (6) evoked response width (for details, see Materials and Methods). PVNs and PyrNs in naive females showed approximately similar frequency tuning properties as indicated by similarities in their mean BF (Fig. $2 a$, compare PyrNs vs PVNs in naive virgins; Table 1). Given that we recorded from approximately the center of A1 the mean BF across mice was roughly in the middle of their hearing range ( $\mathrm{BF}$ of PyrNs = $11.8 \pm 4.4, n=20$ mice, 74 neurons). Indeed, cotuning of local excitatory and inhibitory neurons is expected because excitatory/ inhibitory balance has been reported previously (Wehr and Zador, 2003; Wu et al., 2008; Tan and Wehr, 2009; Moore and Wehr, 2013).

Besides BF, PVNs and PyrNs differed in all other parameters. Compared with PyrNs, PVNs have higher spontaneous spike rates and higher evoked responses (Fig. $2 b, c, f$, compare PVNs in magenta with PyrNs in green; Table 1). The higher evoked spike rate of PVNs is attributed to the generation of zero to four spikes per trial versus zero to one spikes generated by PyrNs (Table 1, Maximum evoked response). Moreover, PVN response latency was significantly faster relative to that of PyrNs (Fig. $2 d, f$; Table 1). We did not find a systematic correlation between the BF and any of the five parameters we tested in either cell type. These data confirm and strengthen previously described results regarding inhibition and excitation in the cortex (Wehr and Zador, 2003; Okun and Lampl, 2008; Zhou et al., 2012; Moore and Wehr, 2013). We next studied whether the transition to motherhood alters the response properties of PyrNs and PVNs, as well as the relationship between these two cell types.

\section{Changes in response properties of L2/3 PVNs and PyrNs in lactating mothers}

The response properties of PVNs and PyrNs in lactating mothers differed from those of naive virgins in several parameters yet remained unchanged in others (Fig. 2; Tables 1, 2). First, the evoked response in L2/3 of lactating mothers was weaker (Tables 1, 2). However, there was no interaction between experimental group and cell type (Fig. $2 c$; Table 2). There were two significant changes in PyrNs between naive virgins and mothers. First, spontaneous firing rates were higher in mothers (Fig. 2b; Tables 1, 2). Second, response width was wider (Fig. 2e; Tables 1, 2). In PVNs, the two other parameters were different. First, response latency was shorter by $3.5 \mathrm{~ms}$ in PVNs of mothers (Fig. 2d; Tables 1, 2). Second, BF was higher in PVNs of mothers versus those in naive virgins (Fig. $2 d$; Tables 1, 2).

Under the assumption that PVNs connect strongly onto PyrNs, we expected that the changes in PVNs (i.e., changes in latency and $\mathrm{BF}$ ) would be accompanied by complimentary changes in PyrNs. For example, we expected that the decrease in response latency of PVNs would induce a similar decrease in PyrNs. However, the changes in PyrNs were in spontaneous activity and response width (Fig. 2d; Tables 1, 2). The decreased latency in PVNs coincided with increased evoked response width of PyrNs (Fig. 2e; Tables 1, 2). This increased evoked response width of PyrNs did not affect their number of maximum evoked response rate per trial (Fig. $2 f$; Table 1 ).

The most prominent effect of motherhood was that the mean BF of PVNs in lactating mothers was found to be $>1$ octave higher than that of PVNs in naive virgins, although PyrN BFs were unchanged between groups (Tables 1, 2; see significant interaction and Fig. 2a). The frequency shift was evident at the level of both single cells and the population. Individual Frequency Response Area (FRA) of PVNs in mothers were similarly sharp as those of naive virgins. Thus, PVNs in mothers seemed to be tuned to higher frequencies at the expense of lower frequencies (Fig. 2g). The shift in BF was evident when we compared PVNs and PyrNs from the same animals (data not shown) and also in the pooled data (Fig. 2a). Additionally, the shift in BF of PVNs is also evident at the population mean FRAs (Fig. $2 g$ ). Moreover, in separate, independent recordings from a different group of lactating mothers (Table 1, Control groups) the mean BF of PVNs was also higher than in naive virgins (Table 
a

b Spont. spike rate, C Evoked response, ${ }_{\text {Response latency, }}$

Response Width, $\mathrm{BF}$,
$\mathrm{kHz}(\log )$ $\mathrm{Hz}(\log )$ $\mathrm{Hz}(\mathrm{log})$
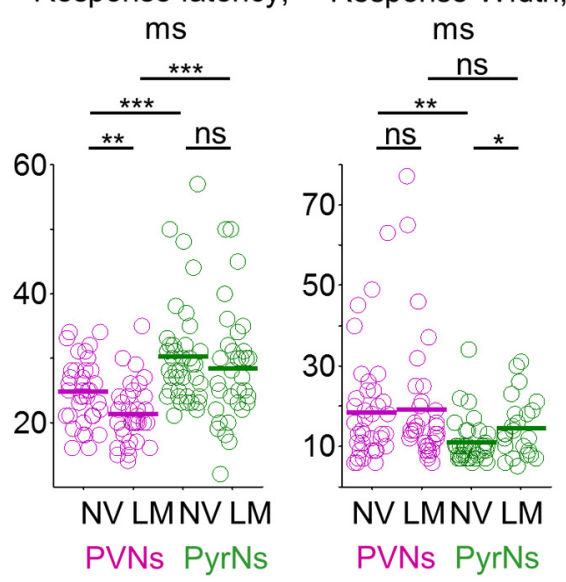

f

$\mathbf{g}$
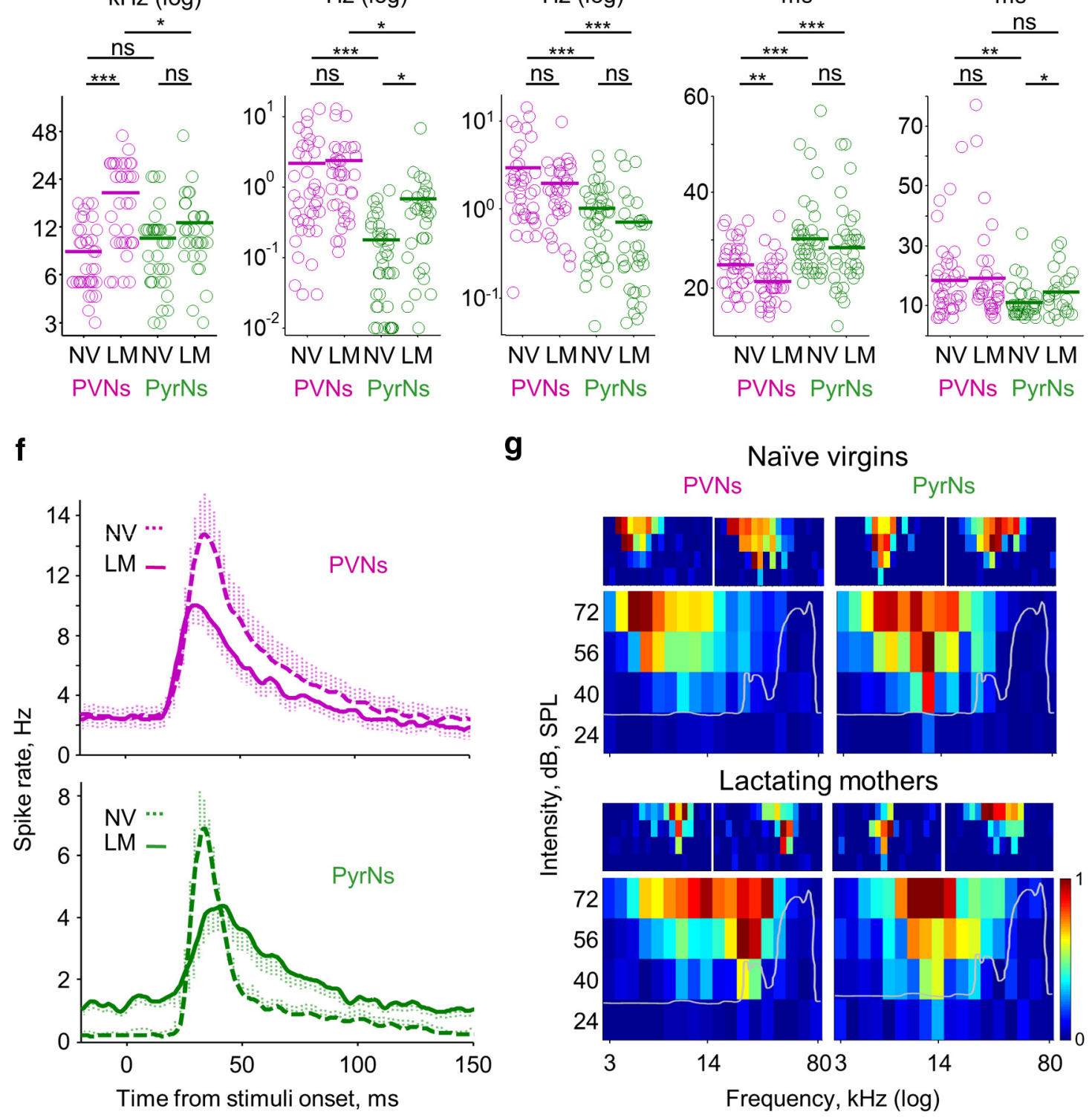

Figure 2. Response properties of PVNs and PyrNs in lactating mothers. $a-e$, Comparative analysis of PVN (magenta) and PyrN (green) response properties in the two experimental groups (Table 1). Each circle represents an individual cell (NV, naive virgins; LM, lactating mothers). The bold line is the mean \pm SEM $\left(2 \times 2\right.$ ANOVA, two-tailed posthoct test; ${ }^{*} p<0.016$, ${ }^{* *} p<0.0033$, ${ }^{* * *} p<$ 0.00033 ; Table 2). $\boldsymbol{f}$, Mean PSTHs of all PVNs (top, magenta) and PyrNs (bottom, green) from both experimental groups (collapsed for all tones and all intensities, binned at spikes/2 ms bins). $\boldsymbol{g}$, FRAs by cell type and experimental group. The larger FRA (bottom) is the mean normalized FRAs of all cells recorded in that experimental group. Two representative examples of single-cell FRAs are shown on the top. The gray line superimposed on the mean FRAs show the spectral-intensity curve of PV $\times$ Ai9 5-d-old pup calls (mean of 6 calls from 3 pups).

Table 2. Statistical analysis of naive virgins versus lactating mothers, PVN versus PyrN physiological properties

\begin{tabular}{|c|c|c|c|c|c|c|c|c|c|c|}
\hline \multirow[b]{2}{*}{ Parameters } & \multicolumn{2}{|c|}{$\begin{array}{l}\text { Spontaneous spike } \\
\text { rate }(\mathrm{Hz})\end{array}$} & \multicolumn{2}{|c|}{ Evoked response (Hz) } & \multicolumn{2}{|c|}{ Response latency (ms) } & \multicolumn{2}{|c|}{$\mathrm{BF}(\mathrm{kHz})$} & \multicolumn{2}{|c|}{$\begin{array}{l}\text { Response width } \\
(50 \%) \text { (ms) }\end{array}$} \\
\hline & $F$ & $p$ & $F$ & $p$ & $F$ & $p$ & $F$ & $P$ & $F$ & $p$ \\
\hline Experimental group & 1.05 & 0.31 & 4.48 & $3.6 \mathrm{e}-2$ & 6.68 & $1 e-2$ & 30.36 & $1.5 \mathrm{e}-7$ & 1.47 & 0.24 \\
\hline Cell type & 22.04 & $6.4 \mathrm{e}-6$ & 24.38 & $2.3 e-6$ & 30.45 & $1.6 \mathrm{e}-7$ & 4.48 & $3.5 \mathrm{e}-2$ & 10.86 & $9 e-4$ \\
\hline Interaction & $6 e-2$ & 0.81 & 1.41 & 0.24 & 0.39 & 0.53 & 11.50 & $9 e-4$ & 1.13 & 0.31 \\
\hline
\end{tabular}

Results of $2 \times 2$ ANOVA with animal group and cell type as factors. The post hoc test results are shown in Figure $2 a-e$.

1). Notably, there was no significant change in the mean BF of PyrNs—not in the general structure of the individual FRAs nor in the population mean FRAs (Fig. 2a,g; Tables 1,2). The correlation coefficient of PVN versus PyrN FRAs was smaller in mothers than in naive virgins ( 0.75 vs 0.85 , with $p=2 \mathrm{e}-11$ vs $p=2 \mathrm{e}-19$, respectively). These data show that the local balance in frequency tuning between PyrNs and PVNs observed in naive virgins is not maintained strictly in mothers. Specifically, the basic properties of feedforward inhibition would be shifted to higher frequencies with regard to the ex- 


$$
\text { a }
$$

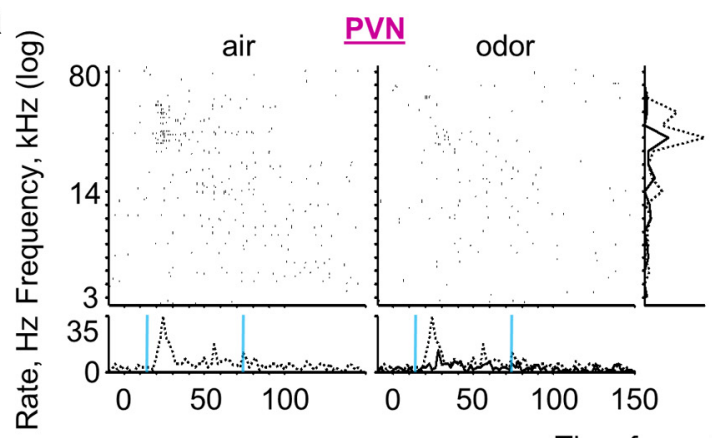

Time from stimuli onset, $\mathrm{ms}$

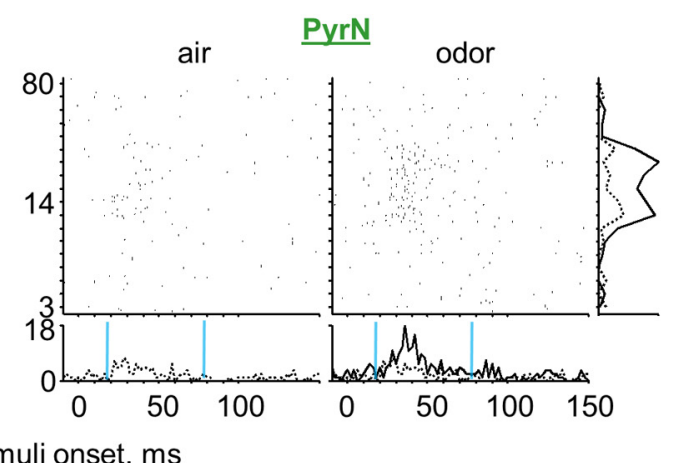

b

Lactating mothers
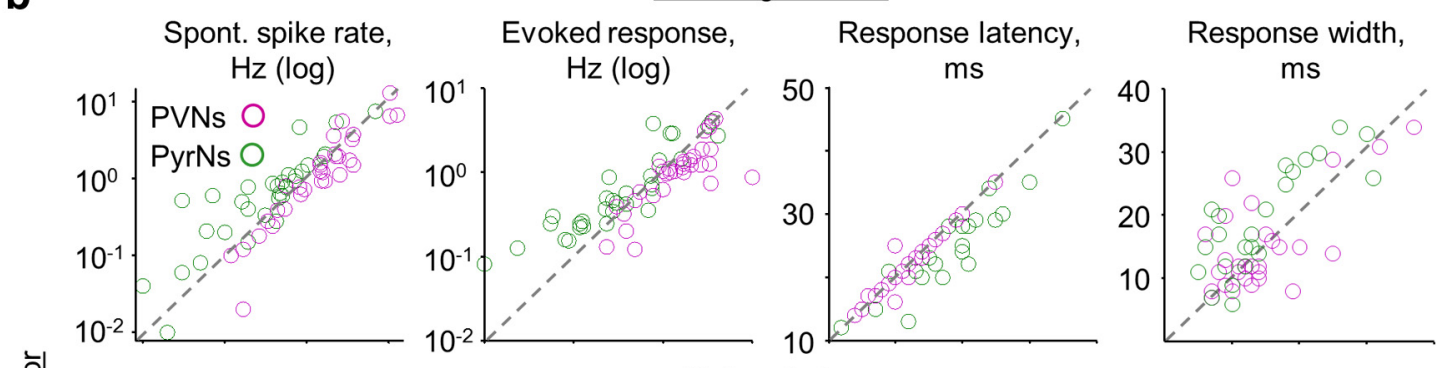

힘
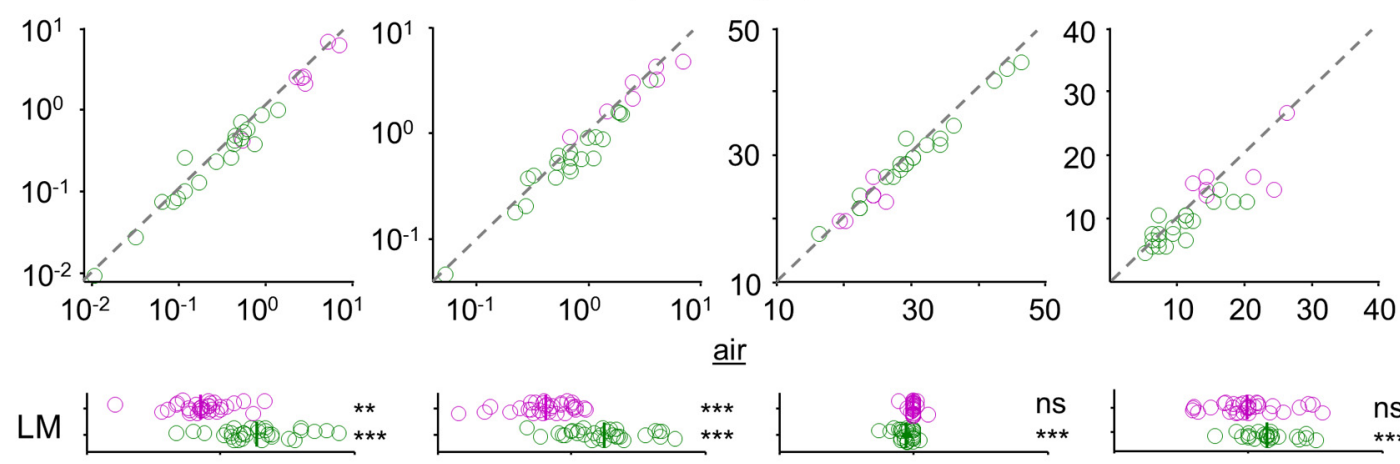

$\underline{\text { air }}$
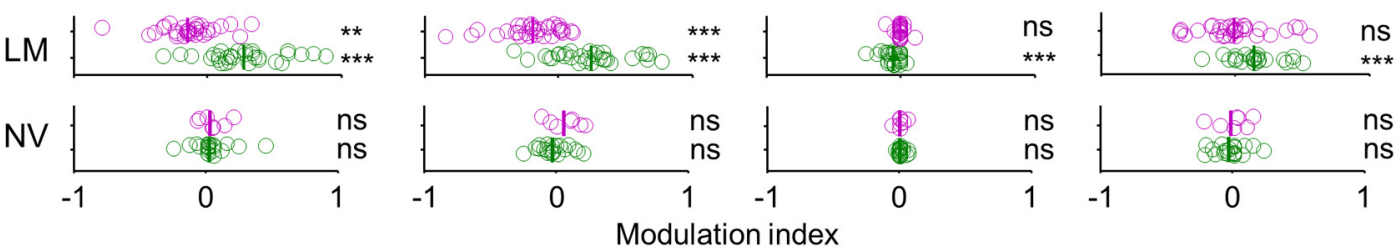

C

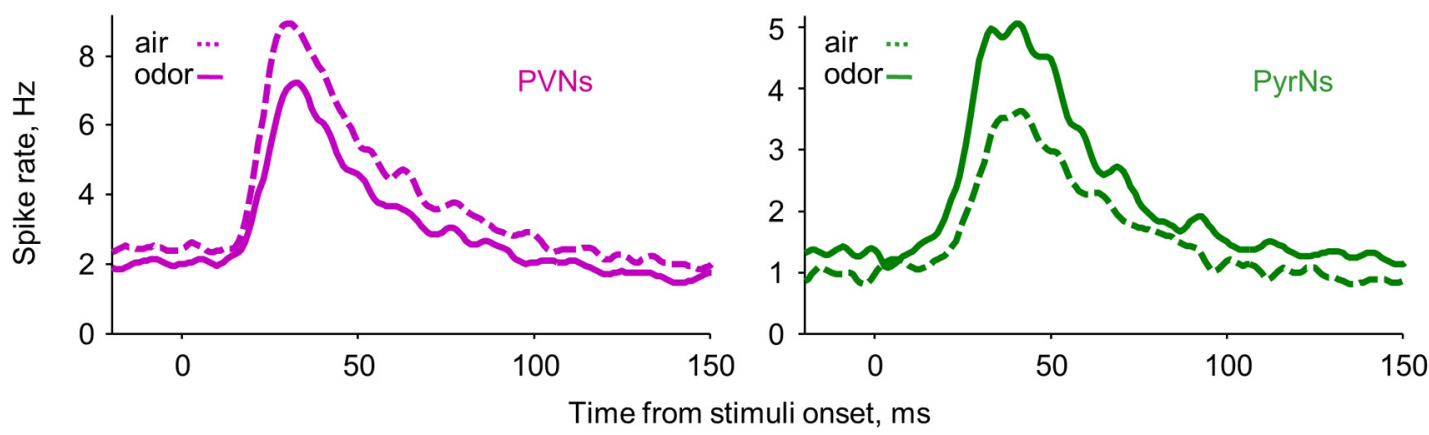

Figure 3. Pup odors induce complementary modulation of PyrN and PyrN response profiles in lactating mothers. $\boldsymbol{a}$, Examples of single-cell raw responses to pure tones, with and without pup odors. For each of the cells, the top shows two raster plots for pure tones (at $56 \mathrm{~dB} \mathrm{SPL}$ ). The left raster was acquired while streaming clear air and the right in the presence of pup odor. The bottom shows PSTHs. Right, Frequency tuning curve. Gray dashed line, Air; black full line, odor. $\boldsymbol{b}$, Scatter plots of individual PVNs (magenta) and PyrNs (green) under clear-air ( $x$-axis) and pup-odor ( $y$-axis) conditions. At the bottom of each plot is the modulation index (see Materials and Methods) for each cell and the population mean (bold line). Top graphs, Lactating mothers; bottom graphs, naive virgin controls (Table 1). Significance of the modulation index was scored using a one-sample $t$ test $\left({ }^{* *} p<0.01,{ }^{* * *} p<0.001\right)$. c, Mean PSTHs of all PVNs and all PyrNs for the lactating mothers group only. The population mean PSTHs represent all frequencies and intensities, binned at spikes/2 ms. 

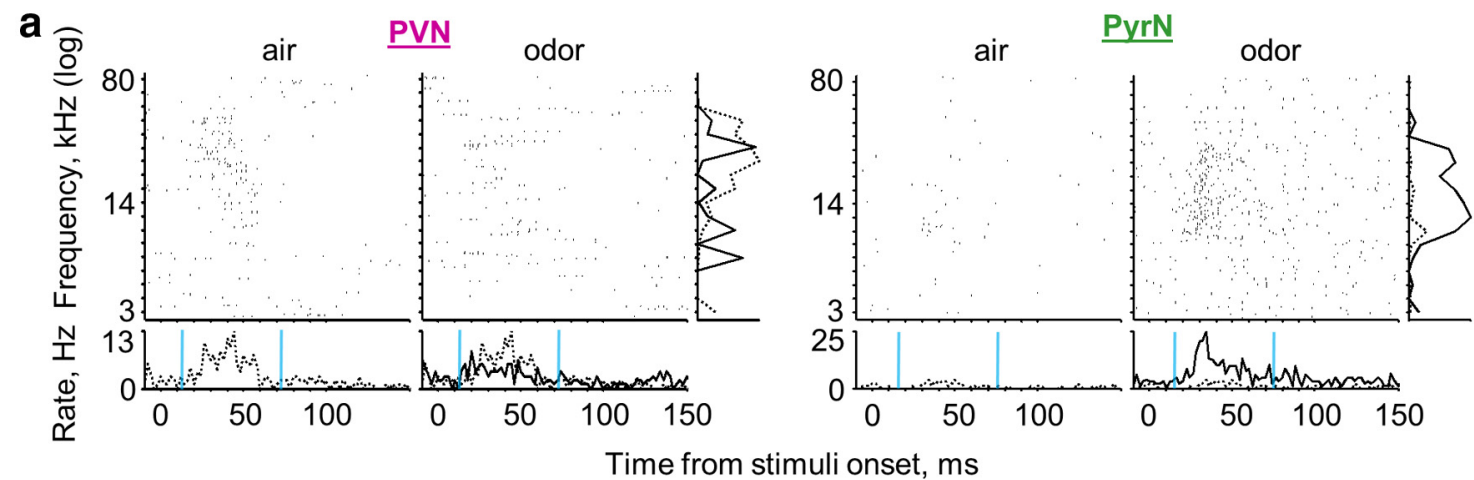

b

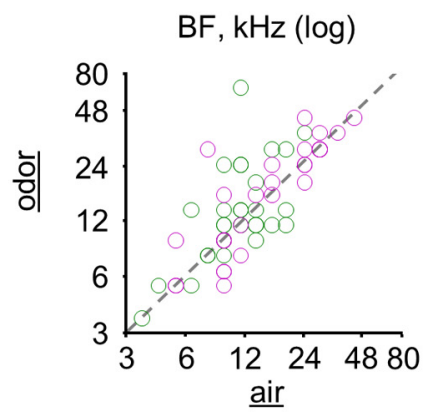

C
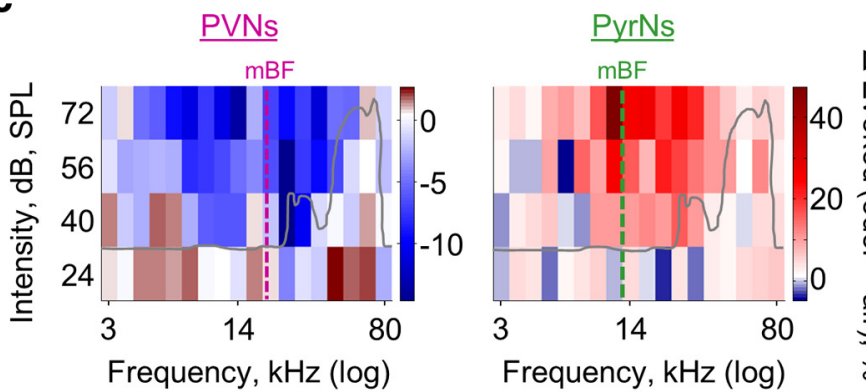

d

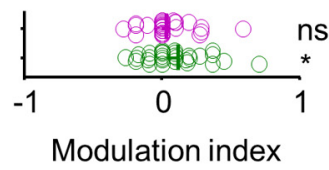

d

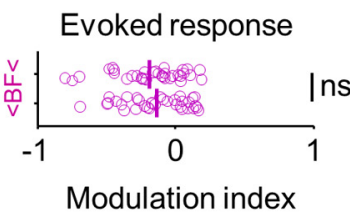

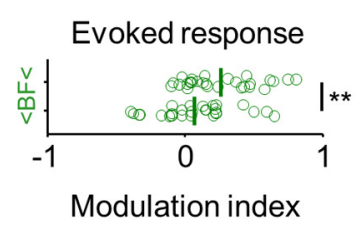

Figure 4. Pup odors induce selective modulation on PVN and PyrN frequency tuning. $\boldsymbol{a}$, Two additional examples of single-cell raw responses to pure tones, with and without pup odors (similar annotation as in Fig. 3a). b, Lactating mothers' PVN (magenta) and PyrN (green) population scatter plots comparing BF of single neurons under clear-air ( $x$-axis) and pup-odor ( $y$-axis) conditions. At the bottom of each plot is the modulation index for each cell and the population mean (bold line). Significant modulation was scored using one-sample $t$ tests ( ${ }^{*} p<0.05$ ). $c$, Top, Residual mean FRAs per cell type. For each cell, we subtracted the air-condition normalized FRA from the odor-condition FRA and calculated the change in percentage. The vertical dashed line indicates the population mean BF per cell type. The gray line superimposed on the mean residual FRAs show the spectral-intensity curve of PV $\times$ Ai9 5 - $d$-old pup calls (mean of 6 calls from 3 pups). $\boldsymbol{d}$, Plots of evoked response (comparing frequencies below and above the BF of the cells) modulation index for each cell and the population mean (bold line). Significant effect was scored using a one-sample $t$ test $\left.{ }^{* *} p<0.01\right)$.

citatory center of PyrNs. We next tested how the addition of pup odors to the stimulus would affect the response profile of the neurons in mothers and whether these changes correlate with the pattern of change under baseline conditions.

\section{In mothers, pup odors modulate the response properties of PyrNs through PVNs}

During the first days after parturition, the mother nurses and protects her pups. Therefore, the mother is almost constantly exposed to the odors of her own pups. We have reported previously that the presence of pup odors induce heterogeneous modulation of neuronal activity in lactating mothers when recordings were done across all layers and cell types of Al (Cohen et al., 2011). Here, we followed up on our previous work by focusing only on L2/3 neurons of mothers and tested whether and how response properties of PVNs and PyrNs were affected by pup odors. We recorded neurons under both clear-air and pup-odor conditions. We scored the response properties of each cell under both clear air (data that were already presented above) and a constant stream of pup body odors. Representative examples of individual PVN and PyrN recordings before and during exposure to pup odors are shown in Figures $3 a$ and $4 a$. Pup odors induced selective and complementary effects on PVNs and PyrNs (Fig. 3).
Pup-odor stimulation significantly reduced PVN spontaneous spike rate and evoked response but increased these parameters in PyrNs (Fig. 3b, two left panels). Pup odors also induced significant changes specific to PyrNs, including a clear decrease in response latency and an increase of evoked response width (Fig. $3 b$; Table 1). These changes in PVN and PyrN evoked response properties are also evident in the mean population PSTHs (Fig. $3 c$ ). In our previous work, we showed that pup odors did not change cortical responses in naive virgins when recordings were made across all layers of A1 (Cohen et al., 2011). To show this for L2/3, we recorded PVNs and PyrNs of naive virgins using the exact same protocol as in mothers (i.e., for each cell, we recorded under both clear-air and pup-odor conditions). Pup-odor stimulation did not change any of the spiking parameters we analyzed in neither PVNs nor PyrNs (Fig. 3b, bottom; Table 1).

In the frequency domain, pup odors induced variable effects on single cells. At the population level, odors induced a slight, but significant, increase in lactating mothers' BF of PyrNs (see examples in Figs. $3 a$ and $4 a$; Fig. $4 b$, Table 1). Although this average change by pup odors is small, it shifts the circuit toward a more balanced condition, compensating in part for the inherent bias of PVNs in mothers (BFs under the pup-odor condition PVNs, $20.7 \pm 12.2$ vs PyrNs, $17.1 \pm 14.5 \mathrm{kHz}$; two-tail $t$ test, $p=0.46$; Table 1). To test more local effects on the cells with regard to 
frequency, we analyzed how the FRAs changed with respect to the $\mathrm{BF}$ of the cell. In response to pup odors, the PVN reduced responses were symmetrical around the BF (Fig. $4 c, d$, left). In contrast, the shift in PyrNs was not symmetrical. Pup odors affected frequencies above the BF of individual cells more pronouncedly than lower frequencies (Fig. $4 c$, $d$, right). This asymmetry toward high frequencies suggests that stimuli, such as USVs, would be particularly affected by pup odors, which we tested next.

Finally, we tested how pup odors affected neuronal response to USVs in mothers. Specifically, we tested responses to USVs recorded from 5 -d-old PV $\times$ Ai9 pups (Fig. 5a). Although the neurons we recorded did respond to high-frequency pure tones, the BF of the vast majority of the cells were lower than the main frequency content of USVs (Fig. $2 a, g$; Table 1). Thus, we expected only few neurons to respond to USVs. Indeed, of the 147 cells recorded under clear-air conditions (PVNs and PyrNs in naive virgins and lactating mothers), only three cells responded to the USV syllables we presented ( $n=0$ of 77 in naive virgins; $n=3$ of 70 in lactating mothers). Two of the cells responsive to USVs under these conditions were PVNs (Fig. 5b, left column, top two cells) and one PyrN (Fig. 5b, bottom cell). As expected from the results of the pure tones (above), pup-odor stimulation inhibited responses of both PVNs to the USVs (Fig. 5b, PVNs; sample was too small for statistical testing, so this observation remains qualitative). Strikingly, pup-odor stimulation significantly increased the number of PyrNs responding to USVs from 1 of 35 to 7 of 35 of the cells (Fisher's exact test on a $2 \times 2$ contingency table with one-tailed test, $p=0.027$; Fig. $5 b$, PyrNs). Thus, pup odors induced a clear increase in responses to USVs, presumably via disinhibition of the feedforward circuitry of the PVNs.

\section{Discussion}

In this work, we describe response properties of excitatory and inhibitory neurons in L2/3 of A1. We compared responses between two experimental groups: naive virgins and lactating mothers. We found that, in mothers, the BF of PVNs is shifted toward higher frequencies, with no significant complementary effect on PyrN tuning. This suggests that the balance between inhibition and excitation is not maintained strictly in motherhood (Fig. 2; Tables 1, 2). Furthermore, we compared the responses of PVNs and PyrNs to sounds under two conditions: with and without the odor of the mother's own pups. Pup odors strongly reduced PVNs responses and concomitantly increased PyrN responses, suggesting that odors induce disinhibition of PyrNs via PVNs. The basal shift of PVN frequency tuning renders pup-odor disinhibition more selective for higher frequencies, as exemplified by increased responsiveness to pup USVs (Figs. 4, 5). Our work identifies that the balance between excitation and inhibition in L2/3 is a possible node in which natural odors and sounds interact in A1.

The transition into motherhood is a major physiological event that is accompanied by multiple changes in the neurochemical environment of the body. Hormones that are upregulated during pregnancy, such as progesterone, drop, whereas hormone levels of prolactin and oxytocin increase. In rodents, oxytocin (either directly or via its receptors) acts via the medial preoptic area and ventral tegmental area to stimulate and orchestrate maternal behaviors (Pedersen et al., 2006; Ross and Young, 2009; Rilling and Young, 2014). Oxytocin seems to play a major role in initiating maternal responses primarily by changing the valence of the pup stimuli from "aversive" in naive virgins to "attractive" in mothers. The direct effects of oxytocin on structures such as the amygdala have been established in the context of both maternal
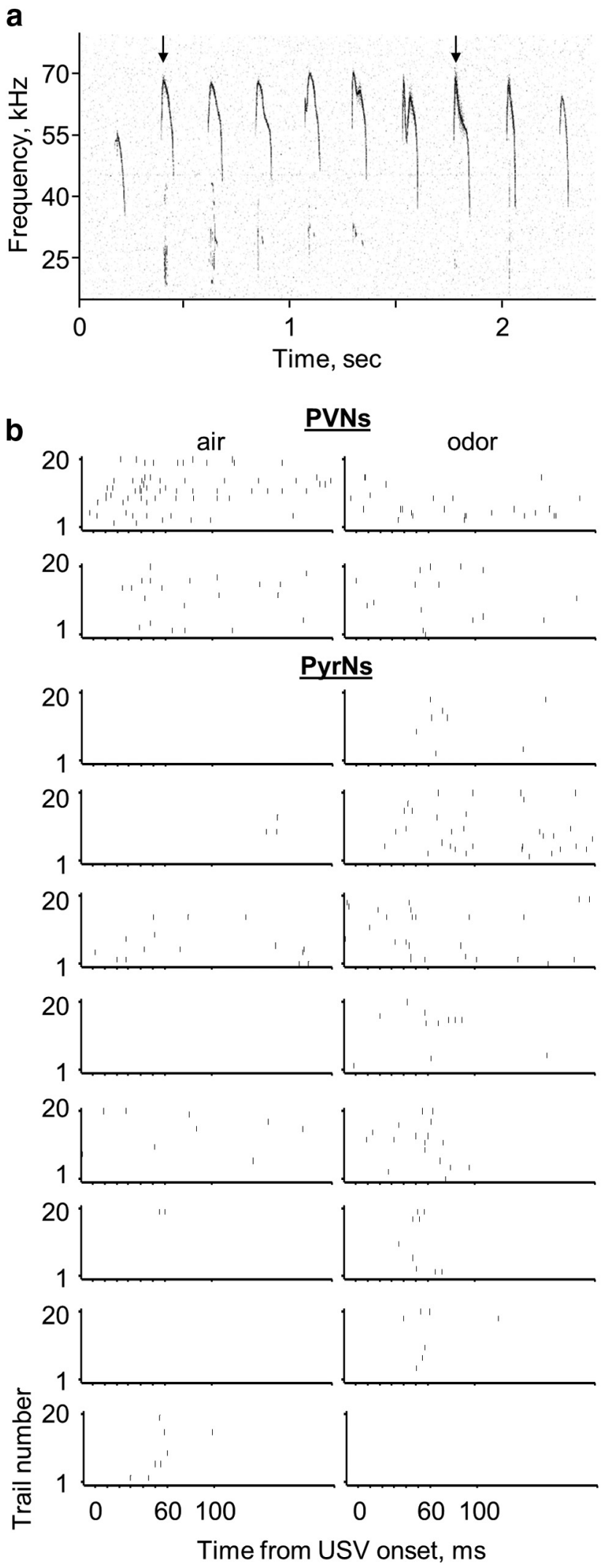

Figure 5. Pup odors increase responses to USV in L2/3 PyrNs. $\boldsymbol{a}$, Spectrogram of a PV $\times$ Ai9 5-d-old pup USV. The black arrows indicate the two syllables used in our auditory protocol (see Materials and Methods). $\boldsymbol{b}$, Raster plots of two PVNs and eight PyrNs that responded to USV syllables during air (left) and odor (right) conditions. 
behaviors and other socially related behaviors (Francis et al., 2000; Ferguson et al., 2001). Oxytocin agonists have been shown to increase inhibition in other brain structures, such as the hippocampus, but their influence on cortical responses are not well established (Stoop, 2012). Oxytocin itself may be regulated by other related hormones, such as estrogen, and in turn regulate the rhythmus of other peptide hormones, such as prolactin (Shughrue et al., 2002; Bertram et al., 2010). The extent to which oxytocin (or other hormones) in the cortex is responsible for the plastic changes we observe in motherhood is not known.

The balance between excitation and inhibition as a possible target of cortical inputs that induce cortical plasticity is gaining increasing attention (for recent reviews in audition, see Carcea and Froemke, 2013; Schreiner and Polley, 2014; Tao et al., 2014). In addition, recent work from the auditory cortex has identified a population of L1 INs in A1 that mediates disinhibitory control in the context of associative learning (Letzkus et al., 2011). In the study by Letzkus et al. (2011), disinhibition was driven by acetylcholine activating L1 INs, which in turn generate inhibition of L2/3 PVNs. Thus, it is well possible that neuromodulatory inputs such as acetylcholine will be mediators of pup odor-induced disinhibition. Additional candidates for disinhibition may originate from vasoactive intestinal peptide (VIP)-expressing INs. During performance of an auditory discrimination task, reinforcement signals strongly and uniformly activated VIP INs in L2/3 of A1 (Pi et al., 2013). In turn, VIP IN recruitment suppresses PVNs and somatostatin INs (targeting the distal dendrites of PyrNs), which in turn increases the gain of PyrNs. Together, it seems that PyrN disinhibitory control in A1 is activated under specific behavioral conditions associated with reward or punishment and is selective for behaviorally relevant stimuli. Similarly, USVs are well positioned to fit this framework of experience-dependent plasticity because they are behaviorally significant.

Auditory responses of PyrNs in supragranular layers of A1 are driven by both thalamocortical and recurrent corticocortical inputs. Because recurrent corticocortical inputs have traveled through additional synapses, they have longer latencies. However, both types of inputs might drive responses with short latencies, particularly at the center of the tuning curve. However, the edges of the tuning curve are thought to be driven primarily by recurrent corticocortical inputs (Liu et al., 2007; Happel et al., 2010; Zhou et al., 2012). The higher spontaneous spike rate and expanded response width of PyrNs in lactating mothers suggests that the recurrent corticocortical inputs to these cells are more effective (Figs. 2e, 3b; Tables 1, 2). Moreover, we showed recently that noise correlations between pairs of $\mathrm{L} 2 / 3 \mathrm{PyrNs}$ in the $\mathrm{A} 1$ of lactating mothers are significantly higher compared with those observed in naive virgins (Rothschild et al., 2013). The high correlations between the activity of L2/3 PyrNs imply that the transition to motherhood increases the probability of corticocortical connections. Such putative altered connectivity together with the pup odor-induced increase in PyrN responses might facilitate the spread of cortical activation by USVs to other regions within and beyond A1.

The transition to motherhood is also associated with other forms of plasticity that affect the temporal balance between excitation and inhibition in A1. In naive virgins, PVN spiking output (known to produce perisomatic IPSCs in PyrNs) precede PyrN EPSC action potential threshold by 5.4 ms (Fig. 2; Tables 1, 2; Wehr and Zador, 2003; Okun and Lampl, 2008; Zhou et al., 2012; Moore and Wehr, 2013). Here, we report that this delicate timing is disrupted in mothers. In the absence of pup odors, PVN spiking output preceded PyrN EPSC action potential threshold by $\sim 8 \mathrm{~ms}$
$(29.2-21.3 \mathrm{~ms}=7.9 \mathrm{~ms}$; Fig. 2; Table 1). Interestingly, this increase was correlated with an increase in $\mathrm{PyrN}$ evoked response width (Fig. 2). Indeed, it was already argued that the earlier onset of feedforward inhibition is expected to increase PyrN EPSC integration time (Zhou et al., 2012). The presence of pup odors reduced the magnitude of feedforward inhibition and accelerated PyrN response latency (by $\sim 2 \mathrm{~ms}$ ). This process restores $\mathrm{PyrN}$ integration time and increases response probability (Fig. 3; Table 1). Moreover, pup-odor stimulation increases the width of $\mathrm{PyrN}$ evoked responses, presumably further improving the integration of late corticocortical inputs (Fig. 3; Table 1). Similarly, it has been shown that pharmacological block of inhibition in A1 reduces PyrN integration time (by $\sim 2 \mathrm{~ms}$ ) and increases response gain (Zhou et al., 2012). Together, the differential effects in our data clearly point to a mechanism of disinhibition by pup odors.

In lactating mothers, the BF of PVNs is centered around higher frequencies compared with naive virgins. As a result, pup odors would reduce feedforward inhibition more prominently at frequencies above the BF of PyrNs. The disinhibition of higher frequencies shifts PyrN tuning toward the ultrasonic band of USVs (Fig. 4) in which excitation and inhibition are again cotuned (Fig. 4; Tables 1,2). Our experiments were all conducted under anesthesia in which experimental rigor is solid but the true natural condition is compromised. In future experiments, it would be interesting to record from freely behaving mothers when the mother is in close proximity of her pups or foraging out of the nest. We speculate that inhibition would play a major role in orchestrating, online, how salient stimuli are coded in A1.

\section{References}

Bertram R, Helena CV, Gonzalez-Iglesias AE, Tabak J, Freeman ME (2010) A tale of two rhythms: the emerging roles of oxytocin in rhythmic prolactin release. J Neuroendocrinol 22:778-784. CrossRef Medline

Brudzynski SM (2009) Communication of adult rats by ultrasonic vocalization: biological, sociobiological, and neuroscience approaches. ILAR J 50:43-50. CrossRef Medline

Brunton PJ, Russell JA (2008) The expectant brain: adapting for motherhood. Nat Rev Neurosci 9:11-25. CrossRef Medline

Carcea I, Froemke RC (2013) Cortical plasticity, excitatory-inhibitory balance, and sensory perception. Prog Brain Res 207:65-90. CrossRef Medline

Chase SM, Young ED (2007) First-spike latency information in single neurons increases when referenced to population onset. Proc Natl Acad Sci U S A 104:5175-5180. CrossRef Medline

Cohen L, Rothschild G, Mizrahi A (2011) Multisensory integration of natural odors and sounds in the auditory cortex. Neuron 72:357-369. CrossRef Medline

Cohen L, Koffman N, Meiri H, Yarom Y, Lampl I, Mizrahi A (2013) Timelapse electrical recordings of single neurons from the mouse neocortex. Proc Natl Acad Sci U S A 110:5665-5670. CrossRef Medline

Dulac C, O'Connell LA, Wu Z (2014) Neural control of maternal and paternal behaviors. Science 345:765-770. CrossRef Medline

Ehret G (2005) Infant rodent ultrasounds-a gate to the understanding of sound communication. Behav Genet 35:19-29. CrossRef Medline

Ferguson JN, Aldag JM, Insel TR, Young LJ (2001) Oxytocin in the medial amygdala is essential for social recognition in the mouse. J Neurosci 21 : 8278-8285. Medline

Fino E, Packer AM, Yuste R (2013) The logic of inhibitory connectivity in the neocortex. Neuroscientist 19:228-237. CrossRef Medline

Francis DD, Champagne FC, Meaney MJ (2000) Variations in maternal behaviour are associated with differences in oxytocin receptor levels in the rat. J Neuroendocrinol 12:1145-1148. CrossRef Medline

Freund TF, Katona I (2007) Perisomatic inhibition. Neuron 56:33-42. CrossRef Medline

Galindo-Leon EE, Lin FG, Liu RC (2009) Inhibitory plasticity in a lateral band improves cortical detection of natural vocalizations. Neuron 62: 705-716. CrossRef Medline

Hahn ME, Lavooy MJ (2005) A review of the methods of studies on infant 
ultrasound production and maternal retrieval in small rodents. Behav Genet 35:31-52. CrossRef Medline

Happel MF, Jeschke M, Ohl FW (2010) Spectral integration in primary auditory cortex attributable to temporally precise convergence of thalamocortical and intracortical input. J Neurosci 30:11114-11127. CrossRef Medline

Hippenmeyer S, Vrieseling E, Sigrist M, Portmann T, Laengle C, Ladle DR, Arber S (2005) A developmental switch in the response of DRG neurons to ETS transcription factor signaling. PLoS Biol 3:e159. CrossRef Medline

Judkewitz B, Rizzi M, Kitamura K, Häusser M (2009) Targeted single-cell electroporation of mammalian neurons in vivo. Nat Protoc 4:862-869. CrossRef Medline

Kitamura K, Judkewitz B, Kano M, Denk W, Häusser M (2008) Targeted patch-clamp recordings and single-cell electroporation of unlabeled neurons in vivo. Nat Methods 5:61-67. CrossRef Medline

Letzkus JJ, Wolff SB, Meyer EM, Tovote P, Courtin J, Herry C, Lüthi A (2011) A disinhibitory microcircuit for associative fear learning in the auditory cortex. Nature 480:331-335. CrossRef Medline

Leuner B, Glasper ER, Gould E (2010) Parenting and plasticity. Trends Neurosci 33:465-473. CrossRef Medline

Lévy F, Keller M (2009) Olfactory mediation of maternal behavior in selected mammalian species. Behav Brain Res 200:336-345. CrossRef Medline

Lévy F, Keller M, Poindron P (2004) Olfactory regulation of maternal behavior in mammals. Horm Behav 46:284-302. CrossRef Medline

Liu BH, Wu GK, Arbuckle R, Tao HW, Zhang LI (2007) Defining cortical frequency tuning with recurrent excitatory circuitry. Nat Neurosci 10 : 1594-1600. CrossRef Medline

Liu RC, Schreiner CE (2007) Auditory cortical detection and discrimination correlates with communicative significance. PLoS Biol 5:e173. CrossRef Medline

Liu RC, Linden JF, Schreiner CE (2006) Improved cortical entrainment to infant communication calls in mothers compared with virgin mice. Eur J Neurosci 23:3087-3097. CrossRef Medline

Lundström JN, Mathe A, Schaal B, Frasnelli J, Nitzsche K, Gerber J, Hummel $\mathrm{T}$ (2013) Maternal status regulates cortical responses to the body odor of newborns. Front Psychol 4:597. CrossRef Medline

Madisen L, Zwingman TA, Sunkin SM, Oh SW, Zariwala HA, Gu H, Ng LL, Palmiter RD, Hawrylycz MJ, Jones AR, Lein ES, Zeng H (2010) A robust and high-throughput Cre reporting and characterization system for the whole mouse brain. Nat Neurosci 13:133-140. CrossRef Medline

Margrie TW, Meyer AH, Caputi A, Monyer H, Hasan MT, Schaefer AT, Denk W, Brecht M (2003) Targeted whole-cell recordings in the mammalian brain in vivo. Neuron 39:911-918. CrossRef Medline

Markram H, Toledo-Rodriguez M, Wang Y, Gupta A, Silberberg G, Wu C (2004) Interneurons of the neocortical inhibitory system. Nat Rev Neurosci 5:793-807. CrossRef Medline

Moore AK, Wehr M (2013) Parvalbumin-expressing inhibitory interneurons in auditory cortex are well-tuned for frequency. J Neurosci 33: 13713-13723. CrossRef Medline

Noirot E (1972) Ultrasounds and maternal behavior in small rodents. Dev Psychobiol 5:371-387. CrossRef Medline

O'Connell MN, Falchier A, McGinnis T, Schroeder CE, Lakatos P (2011) Dual mechanism of neuronal ensemble inhibition in primary auditory cortex. Neuron 69:805-817. CrossRef Medline

Okabe S, Nagasawa M, Kihara T, Kato M, Harada T, Koshida N, Mogi K, Kikusui T (2013) Pup odor and ultrasonic vocalizations synergistically stimulate maternal attention in mice. Behav Neurosci 127:432-438. CrossRef Medline

Okun M, Lampl I (2008) Instantaneous correlation of excitation and inhibition during ongoing and sensory-evoked activities. Nat Neurosci 11: 535-537. CrossRef Medline

Oswald AM, Reyes AD (2011) Development of inhibitory timescales in auditory cortex. Cereb Cortex 21:1351-1361. CrossRef Medline
Pedersen CA, Vadlamudi SV, Boccia ML, Amico JA (2006) Maternal behavior deficits in nulliparous oxytocin knockout mice. Genes Brain Behav 5:274-281. CrossRef Medline

Pfeffer CK, Xue M, He M, Huang ZJ, Scanziani M (2013) Inhibition of inhibition in visual cortex: the logic of connections between molecularly distinct interneurons. Nat Neurosci 16:1068-1076. CrossRef Medline

Pi HJ, Hangya B, Kvitsiani D, Sanders JI, Huang ZJ, Kepecs A (2013) Cortical interneurons that specialize in disinhibitory control. Nature 503: 521-524. CrossRef Medline

Rilling JK, Young LJ (2014) The biology of mammalian parenting and its effect on offspring social development. Science 345:771-776. CrossRef Medline

Ross HE, Young LJ (2009) Oxytocin and the neural mechanisms regulating social cognition and affiliative behavior. Front Neuroendocrinol 30:534547. CrossRef Medline

Rothschild G, Nelken I, Mizrahi A (2010) Functional organization and population dynamics in the mouse primary auditory cortex. Nat Neurosci 13:353-360. CrossRef Medline

Rothschild G, Cohen L, Mizrahi A, Nelken I (2013) Elevated correlations in neuronal ensembles of mouse auditory cortex following parturition. J Neurosci 33:12851-12861. CrossRef Medline

Scattoni ML, Crawley J, Ricceri L (2009) Ultrasonic vocalizations: a tool for behavioural phenotyping of mouse models of neurodevelopmental disorders. Neurosci Biobehav Rev 33:508-515. CrossRef Medline

Schreiner CE, Polley DB (2014) Auditory map plasticity: diversity in causes and consequences. Curr Opin Neurobiol 24:143-156. CrossRef Medline

Sewell GD (1970) Ultrasonic communication in rodents. Nature 227:410. CrossRef Medline

Shughrue PJ, Dellovade TL, Merchenthaler I (2002) Estrogen modulates oxytocin gene expression in regions of the rat supraoptic and paraventricular nuclei that contain estrogen receptor-beta. Prog Brain Res 139: 15-29. CrossRef Medline

Smotherman WP, Bell RW, Starzec J, Elias J, Zachman TA (1974) Maternal responses to infant vocalizations and olfactory cues in rats and mice. Behav Biol 12:55-66. CrossRef Medline

Stiebler I, Neulist R, Fichtel I, Ehret G (1997) The auditory cortex of the house mouse: left-right differences, tonotopic organization and quantitative analysis of frequency representation. J Comp Physiol A Neuroethol Sens Neural Behav Physiol 181:559-571. CrossRef Medline

Stoop R (2012) Neuromodulation by oxytocin and vasopressin. Neuron 76: 142-159. CrossRef Medline

Swain JE, Kim P, Ho SS (2011) Neuroendocrinology of parental response to baby-cry. J Neuroendocrinol 23:1036-1041. CrossRef Medline

Tan AY, Wehr M (2009) Balanced tone-evoked synaptic excitation and inhibition in mouse auditory cortex. Neuroscience 163:1302-1315. CrossRef Medline

Tao HW, Li YT, Zhang LI (2014) Formation of excitation-inhibition balance: inhibition listens and changes its tune. Trends Neurosci 37:528530. CrossRef Medline

Wehr M, Zador AM (2003) Balanced inhibition underlies tuning and sharpens spike timing in auditory cortex. Nature 426:442-446. CrossRef Medline

Wu GK, Arbuckle R, Liu BH, Tao HW, Zhang LI (2008) Lateral sharpening of cortical frequency tuning by approximately balanced inhibition. Neuron 58:132-143. CrossRef Medline

Xu X, Roby KD, Callaway EM (2010) Immunochemical characterization of inhibitory mouse cortical neurons: three chemically distinct classes of inhibitory cells. J Comp Neurol 518:389-404. CrossRef Medline

Yazaki-Sugiyama Y, Kang S, Câteau H, Fukai T, Hensch TK (2009) Bidirectional plasticity in fast-spiking GABA circuits by visual experience. Nature 462:218-221. CrossRef Medline

Zhou Y, Mesik L, Sun YJ, Liang F, Xiao Z, Tao HW, Zhang LI (2012) Generation of spike latency tuning by thalamocortical circuits in auditory cortex. J Neurosci 32:9969-9980. CrossRef Medline 